\title{
A new journey in the new year
}

\section{Muhammad Khurram Khan ${ }^{1}$}

Published online: 16 January 2019

(c) Springer Science+Business Media, LLC, part of Springer Nature 2019

It is always great to celebrate the arrival of new year with passion and enthusiasm of more productive by our newly developed and envisioned plans. As the new year begins, there are new ambitions, dreams, and resolutions that we hope to achieve. I just remember a famous quote of Plato, "The beginning is the most important part of the work", which reminds us to jump start implementing our ideas and dreams to be on the journey of success. Here, I take opportunity to extend my best wishes to all for their new plans and dreams for the new year. May this year bring new joys, achievements and a lot of new inspirations, and I sincerely hope that every day of the new year becomes full of success, prosperity and happiness to all.

The last year has been very productive yet busy in the pursuit of our previously set goals for the Telecommunication Systems (TELS) journal. It gives me immense pleasure to share that TELS is progressing well and improving its stature to achieve excellence with respect to the quality of published contents. Indeed, it is not possible without our great team, which comprise of authors, readers, reviewers, editors, advisory board, editorial and production staff, etc.

To meet the satisfaction of contributing authors, it is of paramount importance to minimize the Journal's turnaround time from submission to the first decision, which remained 48.2 days during 2018 . It is worth mentioning that contributing authors overall satisfaction and publishing experience with TELS remained overwhelming with 93\% score, which manifests the efforts and hard work of the whole team. We are committed to improve the overall satisfaction of our authors as per their expectations without compromising the quality of the journal.
The new innovations and emergence of enabling technologies in telecommunications field keep us busy with ground-breaking and novel submissions to TELS. The editorial board members along with the reviewing teams are a great source of help in soliciting, reviewing, and recommending the best papers to publish. It's fortunate that we have a great editorial board to help us achieving the vision and mission of this journal by their valuable time and relentless efforts, which are indeed much appreciated and commendable. In addition, it is important here to give acknowledgment and appreciation to the departing editorial board members, and welcoming the new members with the hope that they would carry on the legacy of commitment, persistence, and excellence during their tenure of service.

Besides, I must not forget to recognize the efforts and contributions of our previous production editor Mr. Robert Darnowsky who had been a great source of support to publish the contents of journal in time. He was substituted by Ms. Radika Devakumar as the new production editor in July 2018 who is proactive, prompt and diligent with her responsibilities.

Once again, I wish you all a happy, prosperous, productive, and fruitful new year!

Publisher's Note Springer Nature remains neutral with regard to jurisdictional claims in published maps and institutional affiliations.
Muhammad Khurram Khan

mkhurram@ksu.edu.sa

http://www.professorkhurram.com

1 Telecommunication Systems (Springer), King Saud University, Riyadh, Saudi Arabia 